\title{
Pengaruh Metode Mc Kenzie Exercise dan Core Stability Exercise terhadap Penurunan Nyeri pada Penderita Hernia Nucleus Pulposus
}

\author{
Redi Tantangan ${ }^{1, *}$, Siti Sarah Bintang ${ }^{2}$, Samuel Ginting ${ }^{3}$ \\ Fakultas Keperawatan dan Fisioterapi, Institut Kesehatan Medistra Lubuk Pakam, Lubuk Pakam, 20512, Indonesia \\ ${ }^{1}$ reditantangan@ gmail.com*; ${ }^{2}$ sarahbintang@ gmail.com; ${ }^{3}$ samuelginting@ gmail.com \\ * corresponding author
}

ARTICLE INFO

Article history

15-08-2021

29-08-2021

$15-09-2021$

Keywords

Mc Kenzie Exercise

Core Stability Exercise

HNP

\section{ABSTRACT}

Hernia Nucleus Pulposus (HNP) is one of the causes of lower back pain due to heavy mechanical loads for a long time. HNP if not treated immediately it can cause fluid buildup and swelling that can cause permanent nerve damage. This study is a quantitative study with a quasi-experimental pre-test-post-test design with a control group divided into 3 groups. The sampling technique was using probability sampling method as many as 30 respondents who visited Grandmed Lubuk Pakam Hospital. The results of the statistical test showed that there was an effect of McKenzie and Core Stability Exercise on reducing pain in patients with HNP with a p value of $0.020<0.05$.

\section{Pendahuluan}

Nyeri punggung pada bagian bawah merupakan 1 dari 10 penyakit terbanyak di Amerika Serikat dengan angka kejadian sekitar 7,6-37\% dimana kejadian tertinggi pada usia 45 sampai 60 tahun. Nyeri punggung pada bagian bawah dapat mengganggu aktivitas sehari-hari, seperti gangguan tidur, jalan dan aktifitas lainnya, bahkan sampai perlu rawat inap untuk evaluasi lebih lanjut [1].

Menurut World Health Organization (WHO) 2012, nyeri punggang bawah juga sering dikeluhkan oleh pegawai kantoran. Nyeri tersebut merupakan ketidak nyamanan bagi mereka. Prevalensi nyeri punggung bawah pada populasi lebih kurang 16.500.000 per tahun di Inggris. Dari keseluruhan nyeri punggung bawah, yang mendapat tindakan operasi berjumlah 24.000 orang pertahunnya [2]. Hernia Nucleus Pulposus (HNP), merupakan salah satu penyebab dari nyeri punggung pada bagian bawah, dimana kondisi ini terjadi protrusi pada discus intervertebralis yang disebabkan karena injury dan beban mekanik yang dalam waktu yang lama. Selain itu karena meningkatnya usia sehingga terjadi perubahan degeneratif yang mengakibatkan kurang lentur dan tipisnya nucleus pulposus [3].

Bahaya dari HNP jika tidak segera ditangani maka dapat menyebabkan penumpukan cairan dan pembengkakan yang dapat menyebabkan kerusakan saraf permanen selain itu akibat dari HNP juga dapat menyebabkan nyeri yang hebat [4]. Berdasarkan hasil survey awal peneliti di Rumah Sakit Grandmed Lubuk Pakam pada tanggal 21 Januari 2021 data menunjukkan penderita HNP dalam kurun waktu 2 bulan terakhir November - Desember 2020 mencapai 39 orang dan di jumpai 2 orang pasien, 1 orang menyatakan mengalami sangat nyeri terutama pada bagian bawah sejak menderita HNP, pasien menyatakan hanya mengkonsumsi obat-obatan untuk mengurangi rasa nyerinya dan tidak pernah melakukan terapi, sedangkan 1 orang lagi menyatakan sudah pernah mengikuti terapi tetapi tidak secara rutin sehingga masih merasakan nyeri terutama pada saat bagun tidur pagi dan setelah melakukan aktivitas seperti berdiri lama ataupun duduk terlalu lama.

Fisioterapi dapat berperan dengan berbagai macam metode untuk mengatasi nyeri yang disebabkan karena akibat HNP diantaranya dengan metode Mc Kenzie Exercise dan Core Stability Exercise. Mc Kenzie Exercise adalah suatu tehnik latihan dengan menggunakan gerakan badan 
terutama kebelakang untuk penguatan dan peregangan otot-otot ekstensor dan fleksor sendi lumbo sacralis sehingga dapat mengurangi nyeri [5], sedangkan Core Stability Exercise merupakan latihan untuk meningkatkan kelompok otot batang tubuh yang mengelilingi tulang belakang dan perut agar dapat mengendalikan posisi dan gerak batang tubuh untuk menghasilkan gerak yang optimal saat beraktivitas [6].

\section{Metode}

Penelitian yang dilakukan merupakan penelitian kuantitatif dengan menggunakan design quasi eksperiment dengan rancangan pre test-post test with control group. Penelitian ini dibagi menjadi 3 kelompok yaitu kelompok 1 Mc.Kenzie Exercise, kelompok 2 Core Stability Exercise dan kelompok 3 kelompok kontrol. Tehnik pengambilam sampel dengan metode Probability Sampling dengan teknik Sampel Rondom Sampling sebanyak 30 responden dengan rincian masing-masing kelompok sebanyak 10 responden yang sudah ditentukan berdasarkan kriteria inklusi dan eksklusi. Penelitian ini dilaksanakan di Ruang Poli Fisioterapi Rumah Sakit Grandmed Lubuk Pakam Kabupaten Deli Serdang pada bulan Juni - Juli 2021. Alat ukur yang digunakan dalam penelitian ini yaitu dengan menggunakan skala nyeri NRS (Numerik Rating Scale) 0-10 dan hasil penelitian di uji secara statistik dengan menggunakan uji Paired Sample TTest dan uji One Way Anova dengan taraf signifikan 95\% [7].Etika penelitian, penelitian ini sudah lolos uji etik (mendapat persetujuan etik) dan mendapat sertifikat etik dari Komisi Etik Penelitian Kesehatan Fakultas Keperwatan Universitas Sumatera Utara pada tanggal 01 Juni 2021 dengan nomor 2298/VI/SP/2021.

\section{Hasil dan Diskusi}

Penelitian ini dilaksanakan selama 6 minggu dan masing-masing responden mendapat terapi sebanyak 3 kali dalam 1 minggu pada kelompok intervensi sedangkan pada kelompok kontrol hanya di observasi tingkat nyerinya. Pengukuran dilakukan dengan menggunakan skala nyeri NSR 0-10. Data yang diperoleh sudah diuji secara statistik dengan hasil sebaran data berdistribusi normal dan data homogen sehingga uji dapat dilanjutkan dengan menggunakan uji Pairet Sample T-Test dan uji One Way Anova. Adapun hasil penelitian yang sudah diuji secara statistik yaitu :

Tabel 1. Hasil Uji Pairet Sample T-Test Penurunan Nyeri HNP Sebelum (Prettest) dan Sesudah (Posttest) di berikan Terapi Mc Kenzie Exercise

\begin{tabular}{lccccc}
\hline \multicolumn{1}{c}{ Nyeri HNP } & n & Mean & $\begin{array}{c}\text { Std } \\
\text { Deviation }\end{array}$ & t & Sig.(2-tailed) \\
\hline $\begin{array}{l}\text { Sebelum Terapi Mc Kenzie } \\
\text { Exercise }\end{array}$ & 10 & 6.90 & 1.197 & & \\
\hline $\begin{array}{l}\text { Sesudah Terapi Mc Kenzie } \\
\text { Exercise }\end{array}$ & 10 & 4.50 & 1.269 & 0.854 & 0.000 \\
\hline
\end{tabular}

Tabel 1. Menunjukkan bahwa bahwa nilai rata-rata sebelum diberikan terapi Mc Kenzie 6.90 dan setelah diberikan terapi terjadi pnurunan rata-rata nyeri yaitu 4.50 dengan nilai p 0.000 yang artinya terdapat perbedaan sebelum dan sesudah terapi.

Tabel 2. Hasil Uji Pairet Sample T-Test Penurunan Nyeri HNP Sebelum (Prettest) dan Sesudah (Posttest) di berikan Terapi Core Stability Exercise

\begin{tabular}{lccccc}
\hline \multicolumn{1}{c}{ Nyeri HNP } & $\mathbf{n}$ & Mean & $\begin{array}{c}\text { Std } \\
\text { Deviation }\end{array}$ & t & Sig.(2-tailed) \\
\hline $\begin{array}{l}\text { Sebelum Terapi Core } \\
\text { Stability Exercise }\end{array}$ & 10 & 6.80 & 1.476 & \multirow{2}{*}{3.284} & 0.009 \\
$\begin{array}{l}\text { Sesudah Terapi Core } \\
\text { Stability Exercise }\end{array}$ & 10 & 5.50 & 1.581 & & \\
\hline
\end{tabular}


Tabel 2. Menunjukkan bahwa bahwa nilai rata-rata sebelum diberikan terapi Core Stability 6.80 dan setelah diberikan terapi terjadi penurunan rata-rata nyeri menjadi 5.50 dengan nilai p 0.009 yang artinya terdapat perbedaan sebelum dan sesudah terapi diberikan.

Tabel 3. Hasil Uji Pairet Sample T-Test Penurunan Nyeri HNP Sebelum (Prettest) dan Sesudah (Posttest) Pada Kelompok Kontrol

\begin{tabular}{cccccc}
\hline Nyeri HNP & $\mathbf{n}$ & Mean & $\begin{array}{c}\text { Std } \\
\text { Deviation }\end{array}$ & $\mathbf{t}$ & Sig.(2-tailed) \\
\hline Sebelum dilakukan Observasi & 10 & 6.10 & 1.524 & \multirow{2}{*}{-0.758} & 0.468 \\
\hline Sesudah dilakukan Observasi & 10 & 6.40 & 1.350 & \\
\hline
\end{tabular}

Tabel 3. Menunjukkan bahwa bahwa nilai rata-rata sebelum dilakukan observasi pada kelompok kontrol 6.10 dan setelah dilakukan observasi rata-rata nyeri menjadi 6.40 dengan nilai $p$ 0.468 yang artinya tidak ada pengaruh sebelum dan sesudah dilakukan observasi pada kelompok kontrol.

Tabel 4. Hasil Uji One Way Anova pada Ketiga kelompok

\begin{tabular}{|c|c|c|c|c|c|c|}
\hline Kelompok & $\mathbf{n}$ & Mean & $\begin{array}{c}\text { Test of } \\
\text { Normality } \\
\text { (Shapiro-Walk) }\end{array}$ & $\begin{array}{c}\text { Test of } \\
\text { Homogeneity } \\
\text { of Variance }\end{array}$ & $\mathbf{F}$ & Sig.(2-tailed) \\
\hline Mc Kenzie Exercise & 10 & 4.50 & 0.061 & \multirow{3}{*}{0.733} & \multirow{3}{*}{4.567} & \multirow{3}{*}{0.020} \\
\hline $\begin{array}{l}\text { Core Stability } \\
\text { Exercise }\end{array}$ & 10 & 5.50 & 0.849 & & & \\
\hline Kelompok Kontrol & 10 & 6.40 & 0.198 & & & \\
\hline
\end{tabular}

Hasil uji statistik pada tabel 4. Menunjukkan bahwa dari ketiga kelompok masing-masing data berdistribusi normal yaitu Mc Kenzie 0.061, Core Stability 0.849 dan Kelompokkontrol 0.198 yang asrtinya lebih besar dari 0.05 dan dari hasil test homogenitas data diperoleh $0.733>0.05$ yang artinya data homogen dan dari hasil uji one way anova diperoleh nilai p $0.020<0.05$ hal ini dapat disimpulkan bahwa dari ketiga kelompok tersebut memiliki perbedaan nilai rata-rata yang signifikan.

Tabel 1. Menunjukkan bahwa bahwa nilai rata-rata sebelum diberikan terapi Mc Kenzie Exercise 6.90 dan setelah diberikan terapi terjadi pnurunan rata-rata nyeri yaitu 4.50 dengan nilai $p$ 0.000 yang artinya terdapat perbedaan sebelum dan sesudah terapi. Pemberian Mc Kenzie Exercise pada responden diberikan 3 kali dalam seminggu selama 2 minggu sehingga masing-masing responden mendapatkan terapi 6 kali, dari hasil penelitian menunjukkan terdapat perbedaan yang signifikant sebelum dan sesudah terapi diberikan hal ini dikarenakan responden dapat mengikuti instruksi ataupun SOP dengan baik selama penelitian berlangsung.

Penelitian ini juga sejalan dengan penelitian yang dilakukan oleh Abrar. M (2016) kepada 16 petani yang mengalami nyeri LBP Myogenic dari hasil penelitiannya disimpulkan bahwa pemberian Mc Kenzie berpengaruh secara signifikan terhadap penurunana nyeri LBP Myogenic dengan hasil uji statistik 0.012 dan dari hasil penelitian disarankan kepada para petani untuk dapat memperhatikan aktivitas yang dilakukan sehari-hari karena aktivitas yang salah dapat memperberat kondisi pasien, selain itu abyar juga menuliskan di dalam penelitiannya bahwa terapi atau latihan dengan metode Mc Kenzie selain untuk mengurangi nyeri juga dapat membuat tulang bagian punggung bawah tidak kaku dan tegang [8].

Setiap responden berbeda-beda dalam menilai nyeri yang dideritanya, skala nyeri merupakan penilaian yang subjektif untuk bisa mengetahui seberapa parah nyeri yang dirasakan seorang individu, hal ini terlihat ketika intervensi yang diberikan sama dan masing-masing orang akan mengalami hasil yang berbeda [9]. Berdasarkan analisis penelitian, efek pemberian Mc Kenzie Exercise sangat berpengaruh ketika semakin sering dilakukan dengan dosis yang sesuai. Latihan yang dilakukan berulang kali dengan tujuan untuk mngurangi nyeri akibat spasme otot 
yang menciptakan gerakan optimal untuk menimbulkan efek penguluran pada struktur jaringan yang mengalami pemendekan.

Pemberian Mc Kenzie Exercise sebanyak 6 kali dapat memberikan penurunan disability yaitu membebaskan kekakuan sendi oleh kapsulo ligamentair tightness dengan ekstensi spine secara intermiten yang akan mereposisi nucleus keposisi anterior sebagai akibat dari penekanan pada diskus bagian dorsal dan peregangan diskus bagian anterior, serta dapat memberikan efek pemanjangan otot sehingga dapat mengurangi rasa nyeri dan spasme pada bagian otot [10]. Selian Mc Kenzie Exercise metode lain yang dapat digunakan untuk mengurangi nyeri HNP yaitu Core Stability Exercise.

Core Stability Exercise juga merupakan salah satu metode terapi yang dapat digunakan untuk mengurangi nyeri pada penderita HNP hal ini dapat dibuktikan dengan hasil penelitian pada Tabel 2. Yang menunjukkan bahwa bahwa nilai rata-rata sebelum diberikan terapi Core Stability 6.80 dan setelah diberikan terapi terjadi penurunan rata-rata nyeri menjadi 5.50 dengan nilai $\mathrm{p}$ 0.009 yang artinya terdapat perbedaan sebelum dan sesudah terapi diberikan.

Penelitian ini sama dengan hasil penelitian yang diperoleh oleh Prabaningtyas. R.A (2021) yang disimpulkan bahwa dari 20 orang pemetik teh yang mengalami nyeri LBP setelah diberikan latihan atau terapi Core Stability Exercise secara rutin selama 6 kali mengalami penurunan nyeri dengan hasil nilai uji data 0.000 . Sehingga disarankan bahwa secara praktis hasil penelitianya dapat digunakan sebagai pertimbangan bagi para fisioterapis untuk membuat suatu program latihan yang dapat mengurangi nyeri [11]

Nyeri pada umumnya dapat terjadi karena adanya pembebanan mekanis terhadap bagian struktus yang sensistif nyeri misalnya pada bagian otot, sendi ataupun pembuluh darah [12]. Core Stability Exercise merupakan suatu terapi atau latihanyang dapat digunakan untuk melatih otot-otot tertentu untuk memberikan stabilisasi tulang khususnya pada bagian tulang belakang. Bukti dari hasil tinjauan secara sistematik menunjukkan bahwa Core stability Exercise merupakan salah satu pengobatan yang efektif untuk pasien yang mengalami nyeri pada bagian punggung bawah [13]

Pada penelitian ini selain ada kelompok intervensi atau perlakuan juga menggunakan kelompok kontrol sebagai pembanding data untuk mengetahui penurunan atau intensitas nyeri pada pasien HNP dari hasil penelitian menunjukkan bahwa pada kelompok kontrol tidak ada pengaruh atau perubahan secara signifikan sebelum dan sesudah dilakukan observasi nyeri karena pada kelompok kontrol tidak diberikan perlakukan hal ini dapat di buktikan dari hasil uji secara statistik pada tabel 3 yaitu nila rata-rata nyeri responden sebelum observasi 6.10 dan setelah dilakukan obserbvasi rata-rata nyerinya menjadi naik yaitu 6.40 dengan nilai p 0.468

Dari ketiga kelompok tersebut juga telah dilakukan uji analisis One Way Anova hal ini untuk melihat berbedaan rata-rata nyeri pada penderita HNP dan setelah dilakukan uji dari ketiga kelompok tersebut terdapat perbedaan rata - rata nyeri yang signifikan dengan nilai $\mathrm{p} 0.020$. hal ini dapat disimpulkan bahwa metode yang digunakan dalam penelitian ini dapat digunakan untuk mengurangi nyeri pada penderita HNP. Hal ini juga didukung oleh teori Kubey dan Mc Kenzie yang menyatakan bahwa Mc.Kenzie Exercise sudah dirancang untuk menurunkan nyeri pada bagian punggung bawah karena efek dari sentralisasi nyeri berada pada daerah lumbal [14].

Kedua metode yang digunakan dalam penelitian ini menunjukkan sama-sama efektif untuk menurunkan intensitas nyeri pada penderita HNP dikarenakan secara prinsip keduanya memiliki efek yang sama, yaitu menguatkan dan merelaksasikan otot-otot stabilitator tulang belakang, memperbaiki postur yang salah sehingga mengurangi tekanan pada sendi dan mengurangi peregangan pada ligamen [15] dan secara keseluruhan dapat meningkatkan hormon $\beta$-endorphine yang berfungsi sebagai analgesik. Oleh karena itu, melakukan terapi dengan metode Mc Kenzie Exercise dan Cor Stability Exercise secara rutin dapat mengurangi intensitas nyeri punggung bawah khususnya pada penderita HNP

\section{Kesimpulan}

Dari hasil penelitian dapat disimpulkan bahwah Mc Kenzie Exercise dan Cor Stability Exercise merupakan kedua metode yang sama-sama efektif dan dapat digunakan untuk mengurangi nyeri pada penderita Hernia Nucleus Pulposus (HNP).Hasil penelitian ini memberi bukti bahwa kedua metode ini efektif digunakan untuk mengurangi nyeri pada penderita HNP oleh karena itu disarankan bagi pasien yang mengalami nyeri HNP agar dapat melakukan terapi secara rutin 
minimal 6 kali selama 2 minggu dan disarankan bagi fisioterpis agar dapat menerapkan kedua metode ini untuk penanganan kasus HNP. Kedua metode ini selain efektif digunakan untuk mengurangi nyeri juga tidak memerlukan atau menggunakan peralatan yang mahal dalam memberikan terapi sehingga lebih efektif digunakan oleh para fisioterpis

\section{Ucapan Terima Kasih}

Terima kasih kepada Kementerian Pendidikan Kebudayaan, Riset dan Teknologi dankepada Lembaga Layanan Pendidikan Tinggi Wilayah I (LLDIKTI) serta Rumah Sakit Grandmed Lubuk Pakam, Kabupaten Deli Serdang. Dengan adanya bantuan dari semua pihak,penelitian ini dapat berlangsung dengan baik semoga hasil penelitian ini dapat bermanfaat untuk masyarakat khususnya pasien yang mengalami stroke non-hemoragik.

\section{Referensi}

[1] Herliana, A., Yudhiono, N. F. \& Fitriyani. Sistem Pakar Diagnosis Penyakit Hernia Nukleus Pulposus Menggunakan Forward Chainning Berbasis Web. Jurnal Kajian Ilmiah, 17(3), p. 86. 2017.

[2] P. Friedrich, J. et al. Reliability and Practicality of the Core Score: Four Dynamic Core Stability Tests Performed in a Physician Office Setting. Clinical Journal of Sport Medicine, 27(4), pp. 409-414. doi: 10.1097/JSM.0000000000000366. 2017.

[3] Fardon, D. F. et al. 'Lumbar disc nomenclature: Version 2.0 Recommendations of the combined task forces of the North American Spine Society, the American Society of Spine Radiology and the American Society of Neuroradiology', Spine Journal. Elsevier Inc, 14(11), pp. 2525-2545. doi: 10.1016/j.spinee.2014.04.022. 2014.

[4] Nasikhatussoraya, N., Octaviani, R. V. \& Julianti, H. P. 'Hubungan Intensitas Nyeri Dan Disabilitas Aktivitas Sehari-Hari Dengan Kualitas Hidup: Studi Pada Pasien Hernia Nukleus Pulposus (Hnp) Lumbal', Jurnal Kedokteran Diponegoro, 5(4), pp. 1364-1377. 2016.

[5] Suputri, E.P. P.,Damayanti.R.M.,\& Gandasari.A.M.N. Pengaruh Mc Kenzie Extension Exercise Terhadap Tingkat Penurunan Skala Nyeri Punggung Bawah. Jurnal Comunity of Publishing in Nursing. Vol.6, No.2. 2018.

[6] Januarshah.Z. 'Pengaruh Latihan Core Stability Statis (Plank dan Side Plank) dan Core Stability Dinamis (Side Lying Hip Abduction dan Oblique Crunch) Tterhadap Keseimbangan', Journal of Physical Education Health and Sport, 3(2), pp. 96-103. doi: 10.15294/jpehs.v3i2.6550. 2016.

[7] Dahlan., S., M. Besar Sampel dan Cara Pengambilan Sampel. Jakarta : Salemba Medika. 2013.

[8] Abrar Muchlas. Pengaruh Pemberian Modified Lumbal Snags dan Mc Kenzie Exercise terhadap Penurunan Nyeri pada Low Back Pain Myogenic.Universitas Muhammadiyah Surakarta. Electronic Theses and Dissertations. http://eprints.ums.ac.id/45964/. 2016.

[9] Roselina, E., Arifin, S. \& Gidion, H. Manajemen Nyeri Pasien Rawat Jalan Pada Kasus Hernia Nukleus Pulposus Melalui Core Stability. Journal of Vocational Program University of Indonesia Volume 2. Nomor 1. Januari - Juni 2014. 2013.

[10] Navariastami.N., Hikayati \& Ningsih. N. Effect of Kenzie Back Exercise on Lower Back Pain Scale of Songket Craftsman. Jurnal Skolastik Keperawatan Vol.1 No.2 Juli-Desember 2015. 2015.

[11] Prabaningtyas. R.A. Efektivitas Core Stability Exercise Terhadap Penurunan Nyeri, Peningkatan Kekuatan Otot, Range of Motion dan Peningkatan Kualitas Fungsional pada Pemetik Teh Dengan Low Back Pain. www. eprints.uny.ac.id. 2021.

[12] Jeon, K., Kim, T. \& Lee, S. H. 'Effects of muscle extension strength exercise on trunk muscle strength and stability of patients with lumbar herniated nucleus pulposus', Journal of Physical Therapy Science, 28(5), pp. 1418-1421. doi: 10.1589/jpts.28.1418. 2016.

[13] Yuniar., Pangkahila.A.,\& Purnawati.S. Pemberian Pilates Exercise dengan Mc Kenzie Exercise dalam Penurunak Skor Disability Di Klinik Bali Chiropractic Denpasar. Universitas Udayana. Majalah Ilmiah Fisioterapi Indonesia Vol.2 No.3. 2014.

[14] Sani. A dan Durahim. D. The Differences Effect of Giving Snags and Mc.Kenzie With Manual Traction and Mc Kenzie For Pain Reduction and Lumbal Disability in HNP Condition. Jurnal Media Kesehatan Politeknik Kesehatan Makasar. Vol. XVI No. 1, Juni 2021. 2019.

[15] Herawati, I.,\& Wahyuni. Pemeriksaan Fisioterapi. Surakarta: Muhammadiyah University Press. 2017. 